The Nepali Math. Sc. Report

Vol. 35, No.1 and 2, 2018

\title{
BIOHEAT TRANSFER EQUATION IN LIVING TISSUE AND SOME APPLICATIONS
}

\author{
DIL BAHADUR GURUNG ${ }^{1}$
}

\begin{abstract}
Mathematical formulation for heat transfer in living tissue is different than an inert material, and is a current growing research interest area for many researchers due to its wide applications in many medical therapies and physiological studies. This interest stems from the rapid advancement of computational technology and advanced numerical mathematical techniques. The paper focuses on review on basic formulations of bio-heat equation proposed so far by several authors in the living tissue and its some applications.
\end{abstract}

Key Words: Bioheat equation, Burn injury, Thermoregulation, Human eye, Dermal regions AMS (MOS) Subject Classification. 92C35.

\section{INTRODUCTION}

All living animals produce heat. This heat is either preserved in the body or transmitted to the environment. Most of the animals like warm-blooded animals; the heat keeps their internal body temperature constant irrespective of the atmospheric temperatures. The process of keeping the body temperature constant with the change of the environment temperature is called thermoregulation. Human body also keeps the internal body temperature (core temperature) constant $\left(\approx 37^{\circ} \mathrm{C}\right)$ despite the normal variations of atmospheric temperatures.

Skin of human body is not only a protective device but its application in the process of body thermoregulation plays an important role in the physiological functions. The biological tissues include the layers of skin, fat, muscle and bone. Moreover, the skin is composed of two stratified layers: epidermis and dermis. Epidermis and dermis are further stratified into five layers and two layers, respectively.

The internal body (muscle and bone) temperature of a normal human body remains exactly constant within $\pm 1^{\circ} \mathrm{F}$ or $\left( \pm 0.6^{\circ} \mathrm{C}\right)$ despite large fluctuations in environmental temperatures. But skin and subcutaneous tissue temperature, in contrast to the core temperature rises and falls with the temperature of surroundings. Thus, we need the mathematical model to understand the mechanism of heat transfer distribution in the layers of human dermal part with the change of surrounding temperatures, and hence on living tissue. The model study is also required for determining the heat flux that causes thermal pain in human body.

It is well known that human eye is relatively a small organ and very complex optical system in the human body. It consists of several sub-domains with different material 
properties, usually have complex geometry. There is no barrier such as skin to protect the eye against the absorption of an external thermal wave; the heat flux can readily interact with the cornea. Invasive methods in measuring eye temperature are normally dangerous. Therefore, heat transfer model with the use of computational methods is the requirement for the temperature distribution study in normal human eye, and in the case of hyperthermia treatment [9].

\section{THERMAL MODEL DUE TO BLOOD PERFUSED TISSUE}

Living tissue differ from non-biological materials primarily because of the presence of vasculature. The large number and the architectural and dimensional variety of blood vessels account for heat transfer process in the tissue. Thus blood perfusion in blood vessels of living biological tissues is a key mechanism for regulating body temperature. Thus heat flux due to blood flow in living tissues fundamentally differs from heat equation in biological tissues than inert materials. Thus the effect of blood flow on heat transfer in living tissue due to complex thermal interaction between the vasculature and tissue has been a topic of current research interest for physiologists, physicians, biomedical engineers, and mathematicians. So, heat transport in biological tissues, which is usually expressed by the bioheat equation, is a complicated process since it involves thermal conduction in tissue, convection, blood perfusion, and the metabolic heat generation [8]. The rate of change of total heat $(Q)$ in a tissue element with respect to time $t$ can be symbolically expressed as

$$
\frac{\partial Q}{\partial t}=\left.\frac{\partial Q}{\partial t}\right|_{\text {Conduction }}+\left.\frac{\partial Q}{\partial t}\right|_{\text {Perfusion }}+\left.\frac{\partial Q}{\partial t}\right|_{\text {Metabolic }}
$$

and hence

$$
\rho c \frac{\partial T}{\partial t}=\nabla \cdot(k \nabla T)+q_{b}+q_{m}
$$

where $\rho$ and $c$ are respectively the density and specific heat of tissue element, $k$ is the thermal conductivity of tissue, $q_{m}$ is the metabolic heat generation rate per unit tissue volume. The first term on right hand side of Eq. (2.2) is accounted due to Fouriers law of conduction. $q_{b}=\left.\frac{\partial Q}{\partial t}\right|_{\text {Perfusion }}$ is the net rate of energy added by the blood per unit volume of tissue, and $T$ is the tissue temperature.

Several authors have developed mathematical models of bioheat transfer based on vasculature study, and blood flow in blood perfused tissue. Pennes [13] was the first to describe quantitative mathematical relationship between blood and tissue for $q_{b}$ based on his experimental results.

\section{BIOHEAT EQUATION MODELS}

Pennes bioheat equation model is considered to be the first describing the explicit heat transfer model equation in living tissue. Many researchers questioned, examined and utilized the underlying assumptions of Pennes theory. Further development by several investigators on bioheat transfer equation is the extended and modified versions of the original work of Pennes. 
3.1. The Pennes Bioheat Equation [1948]. The Pennes model [13] was initially developed for predicting heat transfer in human forearm based on his experimental results. He proposed a bioheat model to describe the effect of blood perfusion and metabolic heat generation on heat transfer within a living tissue. Since the landmark paper by Pennes, his model has been widely used by many researchers for the analysis of bioheat transfer phenomena in living tissue, so now a days bioheat equation is also called Pennes bioheat equation after his name. His bioheat equation model is based on the following four simplifying assumptions $[7]$ :

1. Equilibrium Site The principal heat exchange between blood and tissue takes place in the capillary beds. The arterioles supplying blood to the capillaries and the venule draining it out. Thus all pre-arteriole and post venule heat transfer between blood and tissue is neglected.

2. Blood Perfusion The flow of blood in the capillaries is assumed to be isotropic. This neglects the effect of blood flow directionality.

3. Vascular Architecture Larger blood vessels in the vicinity of capillary beds play no role in the energy exchange between tissue and capillary blood. Thus the Pennes model does not consider the local vascular geometry.

4. Blood Temperature Blood is assumed to reach the arterioles supplying the capillary beds at the body core temperature. It instantaneously exchanges energy and equilibrates with the local tissue temperature.

Based on these assumptions, Pennes modeled blood effect as an isotropic heat source or sink. The net heat transferred from the blood to the tissue, $q_{b}$, was proportional to blood flow rate and the difference between the arteriole blood temperature, $T_{a}$, entering the tissue and the venous blood temperature, $T_{v}$, leaving the tissue

$$
q_{b}=\omega \rho_{b} c_{b}\left(T_{a}-T_{v}\right)
$$

Since the temperature of the venous blood leaving the tissue depends on the degree of thermal equilibration it undergoes with the surrounding tissue, Pennes introduced a thermal equilibration parameter, $\lambda$, to account for this effect, which is assumed to be uniform throughout the tissue:

$$
T_{v}=T+\lambda\left(T_{a}-T\right)
$$

Substituting in Eq.(3.1)

$$
q_{b}=\omega \rho_{b} c_{b}(1-\lambda)\left(T-T_{a}\right)
$$

Pennes assumed $0 \leq \lambda \leq 1$, although he considered $\lambda=0$, that is, complete thermal equilibration, the venous blood leaving the tissue is $T$, the tissue temperature. For $\lambda=1$, the venous blood leaves the tissue at a temperature equal to the entering arterial blood temperature. At this point, the Pennes derivation assumes that $T_{a}$ is uniform throughout the tissue at some body core temperature, $T_{a 0}$, which Pennes set equal to the mean brachial artery temperature in his experimental subjects, and $\lambda$ is close to zero everywhere in the 
muscle layer, thus yielding the familiar Pennes perfusion heat source term

$$
q_{b}=\omega \rho_{b} c_{b}\left(T_{a 0}-T\right)
$$

Thus following Pennes suggestion, the thermal energy balance equation for perfused tissue is expressed in the following form

$$
\rho c \frac{\partial T}{\partial t}=\nabla \cdot(K \nabla T)+\omega \rho_{b} c_{b}\left(T_{a 0}-T\right)+q_{m}
$$

Pennes performed a series of experimental studies to validate his model. Validations have shown that the results of Pennes bioheat model are in reasonable agreement with the experimental data. Despite reasonable agreement with experimental data, there exist some shortcomings in his model due to its inherent simplicity. The shortcomings of Pennes model come from the basic assumptions that are introduced in this model. These shortcomings can be listed as follows [7]

1. Thermal equilibration does not occur in the capillaries, as Pennes assumed. Instead it takes place pre-arteriole and post-venule vessels having diameters ranging from $70-500 \mu \mathrm{m}$.

2. Directionality of blood perfusion is an important factor in the interchange of energy between vessels and tissue. The Pennes equation does not account for this effect.

3. Pennes equation does not consider the local vascular geometry. Thus significant features of the circulatory system are not accounted for. This includes energy exchange with large vessels, countercurrent heat transfer between artery-vein pairs and vessel branching and diminution.

4. The arterial temperature varies continuously from the deep body temperature of the aorta to the secondary arteries supplying the arterioles, and similarly for the venous return. Thus, contrary to Pennes assumption, pre-arteriole blood temperature is not equal to body core temperature and vein return temperature is not equal to the local tissue temperature, $T$. Both approximations overestimate the effect of blood perfusion on local tissue temperature.

3.2. W Perl Model [1962]. Perl [14] model does not outline the inherent shortcomings in Pennes model but developed the bioheat equation based on his experimental results using local heat clearance method. Perl heat transfer model associates Ficks perfusion principle with the heat conduction and a metabolic term to give partial differential equations for the distribution in space and time of heat in living perfused tissue. He assumed that the rate of heat change in tissue element due to blood perfusion is based on Ficks law of perfusion " the rate of change of a quantity $Q$ of a substance in an organ due to perfusion equals the rate of inflow of substance via arterial blood minus rate of outflow of substance via the venous blood'. The rate of inflow of substance is the product of concentration of substance $C_{a}$ in the arterial blood and the rate of inflow $F_{a}$ of arterial blood. Thus

$$
\left.\frac{\partial Q}{\partial t}\right|_{\text {Perfusion }}=F_{a} C_{a}-F_{v} C_{v}
$$

where $F_{v}$ the rate of blood flow in venous blood vessels, and $C_{v}$ is the concentration of substance in venous blood. 
Eq. (3.6) is applied to a volume of tissues, $\triangle V$, which is not too large and not too small. To fix ideas, the volume element $\triangle V$ is visualized as a cube containing $10^{4}$ cells, which for a cell size of 20 micron has a volume of $0.08 \mathrm{~mm}^{3}$ and an edge length $0.43 \mathrm{~mm}$. The substance of interest can enter and leave the volume element by perfusion, and is given by

$$
\left.\frac{\partial(\triangle Q)}{\partial t}\right|_{\text {Perfusion }}=\left(\triangle F_{a}\right) C_{a}-\left(\triangle F_{v}\right) C_{v}
$$

where $\triangle Q$ is the amount of substance in the volume element $\triangle V$ due to perfusion, $\triangle F_{a}$ is the total rate of blood flow in all the arterioles intersecting the surface of $\triangle V$ measured as the sum of the rates of flow in the individual arterioles. Similar definition is applied for $\triangle F_{v}$. Dividing both sides of Eq. (3.7) by $\triangle V$, we get

$$
\frac{\partial}{\partial t}\left(\frac{\triangle Q}{\triangle V}\right)=\left(\frac{\triangle F_{a}}{\triangle V}\right) C_{a}-\left(\frac{\triangle F_{v}}{\triangle V}\right) C_{v}
$$

Thus

$$
\left.\frac{\partial C}{\partial t}\right|_{\text {Perfusion }}=\phi_{a} C_{a}-\phi_{v} C_{v}
$$

where $C=\frac{\Delta Q}{\Delta V}$ is the tissue concentration of substance which is a function of position and time, $\phi_{a}=\frac{\triangle F_{a}}{\Delta V}$ is arteriole blood perfusion rate, and $\phi_{v}=\frac{\Delta F_{v}}{\Delta V}$ is the venule blood perfusion rate. In case of heat flow, the concentration is thermal energy per unit volume, i.e., the product of density, specific heat and rate of change of temperature. Hence, for heat flow, Eq. (3.9) becomes

$$
q_{b}=\left.\rho c \frac{\partial T}{\partial t}\right|_{\text {Perfusion }}=\rho_{b} C_{b}\left(\phi_{a} T_{a}-\phi_{v} T_{v}\right)
$$

Then the bioheat equation due to Perl is given by

$$
\rho c \frac{\partial T}{\partial t}=\nabla \cdot(K \nabla T)+\rho_{b} c_{b} \phi\left(T_{a}-T_{v}\right)+q_{m}
$$

In the model if it is assumed that the temperature of venous blood exit from capillaries equals local tissue temperature, $T$, or $T_{v}=T$, and $\phi_{a}=\phi_{v}=\phi$. Then the Perl bioheat transfer equation reduces into Pennes bioheat equation

$$
\rho c \frac{\partial T}{\partial t}=\nabla \cdot(K \nabla T)-\rho_{b} c_{b} \phi\left(T-T_{a}\right)+q_{m}
$$

3.3. Wulff Continuum Model [1974]. Due to the simplicity of the Pennes model, many investigators have looked into the validity of the assumptions used to develop the Pennes bioheat equation, in particular the thermal contribution of the flowing blood. Wulff [21] study was the first questioned for the assumptions of the Pennes model for thermal contribution of the flowing blood. Wulff assumed that the heat transfer between flowing blood and tissue should be modeled to be proportional to the temperature difference between these two media rather than between the two bloodstream temperature (i.e., the temperature of the blood entering and leaving the tissue.). Thus, Wulff suggested that the blood flow contribution must be modeled by a directional term of the form $\rho_{b} c_{b} U_{h} \cdot \nabla T$ rather 
than the scalar perfusion term $\omega \rho_{b} c_{b}\left(T_{a 0}-T\right)$ suggested by Pennes, where $U_{h}$ is the local mean blood velocity. Then the simplified bioheat equation due to Wulff is given by

$$
\rho c \frac{\partial T}{\partial t}=\nabla \cdot(K \nabla T)-\rho_{b} c_{b} U_{h} \cdot \nabla T+q_{m}
$$

The main challenge in solving this bioheat equation is in the evaluation of the local blood mass flux $\rho_{b} U_{h}$.

3.4. Chen and Holmes Model [1980]. The modeling work of Chen and Holmes is a microvascular model similar to Wulff. The Chen and Holmes [2] model assumes that the total tissue control volume $\delta V$ is composed of the solid-tissue subvolume $\left(V_{s}\right)$ and blood subvolume $\left(V_{b}\right)$. Using a simplified volume-averaging technique, the energy balance equations for both the solid tissue space and vascular spaces can be written as follows:

\section{Solid Phase:}

$$
\delta V_{s} \rho_{s} c_{s} \frac{\partial T_{s}}{\partial t}=\delta Q_{k s}+\delta Q_{b s}+\delta Q_{m}
$$

where $\rho_{s}$ and $c_{s}$ are the solid tissue density and specific heat, respectively, $\delta Q_{k s}$ is the conductive heat gain, $\delta Q_{b s}$ is the heat gain from the blood subvolume, and $\delta Q_{m}$ is the metabolic heating. The energy balance equation for the vascular space is similar to Eq. (3.14) except with an additional term associated with the bulk fluid flow in this space.

\section{Fluid Phase:}

$$
\delta V_{b} \rho_{b} c_{b} \frac{\partial T_{b}}{\partial t}=\delta Q_{k b}-\delta Q_{b s} \int_{S} \rho_{b} c_{b} T \vec{u} \cdot d S
$$

Where $\rho_{b}$ and $c_{b}$ are the blood density and specific heat, respectively, $\delta Q_{k b}$ is the conductive contribution, and the integral term in Eq. (3.15) denotes the energy transfer by convection as the blood flows across the surface area $S$ at velocity $\vec{u}$.

Addition of Eq. (3.14) to Eq. (3.15), and dividing by $\delta V$ results in

$$
\rho c \frac{\partial T}{\partial t}=q_{k}+q_{p}+q_{m}
$$

where $\rho$ and $c$ are

$$
\rho=\left(1-\phi_{b}\right) \rho_{s}+\phi_{b} \rho_{b} \quad \text { and } \quad c=\frac{1}{\rho}\left[\left(1-\phi_{b}\right) \rho_{s} c_{s}+\phi_{b} \rho_{b} c_{b}\right]
$$

where $\phi_{b}=\frac{\delta V_{b}}{\delta V}$ is the porosity of tissue where blood flows, and $T$ is the local mean tissue temperature expressed as

$$
T=\frac{1}{\rho c}\left[\left(1-\phi_{b}\right) \rho_{s} c_{s} T_{s}+\phi_{b} \rho_{b} c_{b} T_{b}\right]
$$

Note that tissue temperature $T$ is approximately equal to $T_{s}$ for $\phi_{b}<<1$, that is, if $\phi_{b}$ approaches zero. The quantity $q_{k}$ denotes the heat transfer by conduction per unit volume, $q_{p}$ is the perfusion energy generated per unit volume, and $q_{m}$ is the metabolic heat generation 
per unit volume. The total heat transfer by conduction per unit volume, $q_{k}$, is assumed to be

$$
q_{k}=\frac{Q_{k s}+Q_{k b}}{\delta V}=\nabla \cdot\left(k_{\mathrm{eff}} \nabla T\right)
$$

where $k_{\text {eff }}$ represents the thermal transport associated with molecular energy of the combined tissue and vascular spaces known as effective thermal conductivity. The effective thermal conductivity is given as

$$
k_{\text {eff }}=\phi_{b} k_{b}+\left(1-\phi_{b}\right) k_{s}
$$

Since $\phi_{b}=\frac{\delta V_{b}}{\delta V} \approx \frac{\delta V_{b}}{\delta V_{s}}<<1$, it follows that $k_{\text {eff }}$ is independent of blood flow and equal to the conductivity of the solid tissue, that is, $k_{\mathrm{eff}}=k_{s}$.

Chen and Holmes found that the blood temperatures of the pre-capillary arterioles, capillaries, and venules were essentially equal to the solid tissue temperatures. In other words, the equilibration between blood and tissue has already occurred before the capillary, not only in the capillary previously suggested by Pennes. They suggested that perfusion heating term in a control volume is based on the blood flow rates and the blood temperatures. Thus the perfusion term is expressed as

$$
q_{p}=\frac{1}{\delta V} \int_{S} \rho_{b} c_{b} T \vec{u} \cdot d S \equiv \rho_{b} c_{b} \omega_{b}\left(T_{a}^{*}-T\right)-\rho_{b} c_{b} \vec{u}_{p} \cdot \nabla T+\nabla \cdot k_{p} \nabla T
$$

where $\omega_{b}$ is the perfusion rate at the local of vessel branching, $T_{a}^{*}$ is the blood temperature, $\vec{u}_{p}$ is the directionality of volumetric blood flow rate per unit area, and $k_{p}$ denotes the perfusion conductivity.

Therefore, the bioheat equation based on the Chen and Holmes model can be written as

$$
\rho c \frac{\partial T}{\partial t}=\nabla \cdot\left(k_{\mathrm{eff}} \nabla T\right)+\rho_{b} c_{b} \omega_{b}\left(T_{a}^{*}-T\right)-\rho_{b} c_{b} \vec{u}_{p} \cdot \nabla T+\nabla \cdot k_{p} \nabla T+q_{m}
$$

Chen and Holmes model represents a significant improvement over Pennes equation. But its application requires detailed knowledge of the vascular network and blood perfusion. This makes it difficult to use.

3.5. Weinbaum and Jiji Model [1985]. Weinbaum and Jiji [19] have developed a mathematical model of bioheat transfer as an alternative to the Pennes bioheat equation. Their objections to the Pennes model include the lack of directionality in the isotropic perfusion term and the neglect of the influence of larger blood vessels embedded in the perfused tissue on the tissue blood heat transfer. In addition, Weinbaum and colleagues criticize the Pennes model for not accounting for the characteristic geometry of the blood vessel arrangement, that is, the branching, tapered diameter ultra structure of the paired, countercurrent arteries and veins as they gradually branch into arteriole, venules, and capillary beds.

Weinbaum and Jiji (WJ) discussed in some limiting case in their Weinbaum, Jiji and Lemon (WJL) [20] model that includes three heat transfer equations for the artery, vein, and tissue, that contains only the tissue temperature and its spatial derivatives resulting too complex model and difficult for solving for the coupling boundary value problem. In 
order to obtain simplified new bioheat equation, Weinbaum and Jiji made the following two major assumptions in addition the assumptions made on their WJL model:

1. The vascularization of tissues behaves as an anisotropic heat transfer mechanism.

2. The mean tissue temperature $T$ is approximated by the average of the local artery, $T_{a}$, and vein, $T_{v}$, temperatures. That is

$$
T=\frac{T_{a}+T_{v}}{2}
$$

3. Rate of energey loss by radial conduction through tissue per unit length of vessel at artery wall, $q_{a}$, is mostly conducted to the corresponding vein:

$$
q_{a} \approx q_{v} \approx \sigma k\left(T_{a}-T_{v}\right)
$$

The shape factor $\sigma$ is associated with the resistance to heat transfer between two parallel vessels embedded in an infinite medium. For the case of vessels of radius $a$, at uniform surface temperatures with center to center spacing $l$, the shape factor is given by

$$
\sigma=\frac{\pi}{\cos h^{-1}(l / 2 a)}
$$

Based on the above assumptions, application of conservation of mass for the artery and vein and conservation of energy for the artery, vein and tissue in the control volume, give the simplified bioheat equation

$$
\rho c \frac{\partial T}{\partial t}=\nabla \cdot\left(k_{\mathrm{eff}} \nabla T\right)+q_{m}
$$

where $k_{\text {eff }}$ is the effective conductivity defined as

$$
k_{\text {eff }}=k\left[1+P e^{2} V(\xi)\right]
$$

where $\xi$ is a dimensionless distance and it defines as $x / L$ and $L$ is the tissue layer thickness. Also, $V(\xi)$ is dimensionless vascular geometry function and it can be calculated if the vascular data are available. Furthermore, $P e$ is the inlet peclet number which is defined as

$$
P e=\frac{2 \rho_{b} c_{b} a_{0} u_{0}}{k_{b}}
$$

where $a_{0}$ and $u_{0}$ are the vessel radius and blood velocity respectively, at the inlet to the tissue layer at $x=0$.

The main limitations of the Weinbaum-Jiji bioheat equation are associated with the importance of the countercurrent heat exchange. It was derived to describe heat transfer in peripheral tissue only, where its fundamental assumptions are most applicable. In tissue area containing a big blood vessel $(>200 \mu \mathrm{m})$, the assumption that most of the heat leaving the artery is required by its countercurrent vein could be violated, thus, it is not an accurate model to predict the temperature field. Furthermore, unlike the Pennes bioheat equation, which requires only the value of local blood perfusion rate, the WJ bioheat model requires many detailed anatomical and vascular data such as the vessel number density, size, and artery-vein spacing for each vessel generation, as well as the blood perfusion rate. These anatomical data are normally not available for most blood vessels in the thermally significant range [22]. 
3.6. Nakayama, Sano and Yoshikawa Model [2010]. This model is also known as volume averaging model for bioheat transfer model. Nakayam, Sano and Yoshikawa [12] (NSY) presented a rigorous mathematical development based on volume averaging theory established in the field of fluid-saturated porous media to derive a general set of bioheat transfer equations for the arterial blood phase, venous blood phase and tissue phase. Further, these three equations were combined together to form a single energy equation in terms of tissue temperature alone. The resulting energy equation turns out to be remarkably simple due to define the effective thermal conductivity tensor, which accounts not only for the countercurrent heat exchange mechanism but also for the thermal dispersion mechanism. Under appropriate conditions, the bioheat equation reduces to earlier developed models from Pennes to WJ.

For the development of energy equation, the authors [12] made the following assumptions:

1. Local anatomical tissue structure is treated as a fluid saturated porous media of three phases arterial blood phase, venous blood phase and solid tissue phase.

2. The control volume $V$ is large enough to include a sufficient number of thermally significant arterial and venous vessels $(40-300 \mu \mathrm{m})$ and at the same time small enough to define volume average quantities locally within the peripheral tissue towards the skin surface.

3. The thermally significant arteries and veins are paired such that the countercurrent heat transfer takes place.

Let $V_{f}$ be the volume space occupied by fluid (blood) in a control volume

(i) Volume average of a variable $\phi$ is defined as

$$
\langle f\rangle=\frac{1}{V} \int_{V_{f}} \phi d V
$$

(ii) Intrinsic average of variable $\phi$ is defined as

$$
\langle\phi\rangle^{f}=\frac{1}{V_{f}} \int_{V_{f}} \phi d V
$$

From above, $\langle\phi\rangle=\epsilon\langle\phi\rangle^{f}$, where $\epsilon=\frac{V_{f}}{V}$ is the local porosity, that is, the volume fraction of the vascular space. If $\epsilon_{a}, \epsilon_{v}$ and $\epsilon_{s}$ are respectively the local porosity for arterial blood, venous blood and tissue, then $\epsilon_{a}+\epsilon_{v}+\epsilon_{s}=1$. If $\langle\tilde{\phi}\rangle$ is a deviation in variable $\phi$, then [16]

$$
\phi=\langle\phi\rangle^{f}+\tilde{\phi}
$$

and

$$
\begin{aligned}
(i)\left\langle\phi_{1} \phi_{2}\right\rangle^{f} & =\left\langle\phi_{1}\right\rangle^{f}\left\langle\phi_{2}\right\rangle^{f}+\left\langle\tilde{\phi}_{1} \tilde{\phi}_{2}\right\rangle^{f} \\
(i i)\left\langle\frac{\partial \phi}{\partial x_{i}}\right\rangle & =\frac{\partial\langle\phi\rangle}{\partial x_{i}}+\frac{1}{V} \int_{\text {int }} \phi \eta_{i} d A=\frac{1}{\epsilon} \frac{\partial\langle\phi\rangle}{\partial x_{i}}+\frac{1}{V_{f}} \int_{\text {int }} \phi \eta_{i} d A \\
\text { (iii) }\left\langle\frac{\partial \phi}{\partial t}\right\rangle & =\frac{\partial\langle\phi\rangle}{\partial t}
\end{aligned}
$$


where $A_{f}$ represents control surface element within the vascular space, $A_{\text {int }}$ represents the interface between the blood and solid matrix within the local control volume, and $\eta_{i}$ is the unit vector pointing outward from the blood side to tissue matrix side.

The microscopic energy equation for blood phase and tissue phase are:

(a) For the fluid (blood) phase

$$
\rho_{f} c_{f}\left(\frac{\partial T_{f}}{\partial t}+\vec{u} \cdot \nabla T_{f}\right)=\nabla \cdot\left(k_{f} \nabla T_{f}\right)
$$

(b) For the solid matrix (tissue) phase

$$
\rho_{s} c_{s} \frac{\partial T_{s}}{\partial t}=\nabla \cdot\left(k_{s} \nabla T_{s}\right)+q_{m}
$$

where $\vec{u}$ is fluid velocity, $\rho_{f}, c_{f}, k_{f}$ are respectively the fluid density, fluid specific heat and fluid thermal conductivity. $\rho_{s}, c_{s}, k_{s}$ are corresponding to solid.

The volume averaging of blood and tissue phases are

(a) For the fluid (blood) phase

$$
\left\langle\rho_{f} c_{f} \frac{\partial T}{\partial t}\right\rangle+\left\langle\rho_{f} c_{f} \frac{\partial}{\partial x_{j}} u_{j} T\right\rangle=\left\langle\frac{\partial}{\partial x_{j}}\left(k_{f} \frac{\partial T}{\partial x_{j}}\right)\right\rangle
$$

(b) For the tissue phase

$$
\left\langle\rho_{s} c_{s} \frac{\partial T}{\partial t}\right\rangle+\left\langle\frac{\partial}{\partial x_{j}}\left(k_{f} \frac{\partial T}{\partial x_{j}}\right)\right\rangle+\epsilon_{s} q_{m}
$$

After some manipulation, the volume averaging for the arterial blood, venous blood and tissue phases are [12]

(a) For arterial blood phase

$$
\begin{aligned}
& \rho_{f} c_{f} \epsilon_{a} \frac{\partial\langle T\rangle^{a}}{\partial t}+\rho_{f} c_{f} \frac{\partial \epsilon_{a}\left\langle u_{j}\right\rangle^{a}\langle T\rangle^{a}}{\partial x_{j}} \\
= & \frac{\partial}{\partial x_{j}}\left(k_{f} \epsilon_{a} \frac{\langle\partial T\rangle^{a}}{\partial x_{j}}+\frac{k_{f}}{V} \int_{\text {int a }} T \eta_{j} d A-\rho_{f} c_{f} \epsilon_{a}\left\langle\tilde{u_{j}} \tilde{T}\right\rangle^{a}\right) \\
+ & \frac{k_{f}}{V} \int_{\text {int a }} \frac{\partial T}{\partial x_{j}} \eta_{j} d A+\frac{\rho_{f} c_{f}}{V} \int_{\text {int a }} u_{j} T \eta_{j} d A
\end{aligned}
$$

(b) For venous blooe phase

$$
\begin{aligned}
& \rho_{f} c_{f} \epsilon_{v} \frac{\partial\langle T\rangle^{v}}{\partial t}+\rho_{f} c_{f} \frac{\partial \epsilon_{v}\left\langle u_{j}\right\rangle^{v}\langle T\rangle^{v}}{\partial x_{j}} \\
= & \frac{\partial}{\partial x_{j}}\left(k_{f} \epsilon_{v} \frac{\langle\partial T\rangle^{v}}{\partial x_{j}}+\frac{k_{f}}{V} \int_{\mathrm{int} \mathrm{v}} T \eta_{j} d A-\rho_{f} c_{f} \epsilon_{a}\left\langle\tilde{u_{j}} \tilde{T}\right\rangle^{v}\right) \\
+ & \frac{k_{f}}{V} \int_{\text {int } \mathrm{v}} \frac{\partial T}{\partial x_{j}} \eta_{j} d A+\frac{\rho_{f} c_{f}}{V} \int_{\mathrm{int} \mathrm{v}} u_{j} T \eta_{j} d A
\end{aligned}
$$


(c) For tissue phase

$$
\begin{aligned}
& \rho_{s} c_{s} \epsilon_{s} \frac{\partial\langle T\rangle^{s}}{\partial t} \\
= & \frac{\partial}{\partial x_{j}}\left(k_{s} \epsilon_{s} \frac{\langle\partial T\rangle^{s}}{\partial x_{j}}-\frac{k_{s}}{V} \int_{\text {int a }+\operatorname{int} \mathrm{v}} T \eta_{j} d A-\rho_{f} c_{f} \epsilon_{a}\left\langle\tilde{u_{j}} \tilde{T}\right\rangle^{a}\right) \\
& -\frac{k_{f}}{V} \int_{\text {int a }+\operatorname{int~v}} \frac{\partial T}{\partial x_{j}} \eta_{j} d A-\frac{\rho_{f} c_{f}}{V} \int_{\text {int a }} u_{j} T \eta_{j} d A+\epsilon_{s} q_{m}
\end{aligned}
$$

Combining the three energy equations under the local thermal equilibrium condition, that is, $\langle T\rangle^{a}=\langle T\rangle^{v}=\langle T\rangle^{s}=\langle T\rangle$, the general bioheat equation for the countercurrent blood flow due to NSY reduces to [12]

$$
\begin{aligned}
& {\left[2 \epsilon_{a} \rho_{f} c_{f}+\left(1-2 \epsilon_{a}\right) \rho_{s} c_{s}\right] \frac{\partial\langle T\rangle^{s}}{\partial t} } \\
= & \frac{\partial}{\partial x_{j}}\left[\left(2 \epsilon_{a} k_{f}+\left(1-2 \epsilon_{a}\right) k_{s}\right) \delta_{j k}+\frac{17\left(\epsilon_{a} \rho_{f} c_{f}\right)^{2} u_{B}^{2} l_{j} l_{k}}{7 a_{a} h_{a}}\right] \frac{\partial\langle T\rangle^{s}}{\partial x_{k}} \\
& +\left(1-2 \epsilon_{a}\right) q_{m}
\end{aligned}
$$

where $a_{a}$ is the specific surface area and $h_{a}$ is the interfacial heat transfer coefficient, and $\left\langle u_{i}\right\rangle^{a}=h_{B} l_{i}$ with $l_{i}$ is the local unit vector along the arterial blood vessel axis, and $\delta_{j k}$ is a Dirac delta function.

\section{Applications}

Despite the inherent shortcomings in Pennes bioheat equation model, many researchers prefer to use Pennes bioheat equation due to its computational simplicity, and its ease to handle in the skin layers, in the layers of human eye and whole body with variable physical and physiological parameters.

There are several applications of bioheat transfer equations. For example, in the existence of thermal gradient between fetal and maternal tissue [10], presence of the global system mobile (GSM) electromagnetic fields in the environment due to causing cellular phones base stations that has adverse health effect [15], hyperthermia treatment for Tumor, cryosurgery, body thermal regulation, frostbite, skin burns, response to environment conditions and thermal stresses, and determination of thermal dose during thermal therapy, thermal sensation during hot and cold touch material, laser treatment, temperature variation in tumor region, thermal distribution models in human eye, comparison of temperature distribution in human male and femal body etc.

\subsection{Temperature Distribution Model in Peripheral Layers of Human Body at}

Stagnant Air. The function of the thermoregulatory system of a homoithermic organism is to maintain a constant body temperature under different environmental conditions. This involves mechanism and adaptations that prevent excessive heat loss or that produce heat in environments colder than the body core temperature, and mechanism and adaptation that prevent excessive heat gain or that remove heat in environments warmer than the body core temperature. These mechanism and adaptation involved in thermoregulation act to balance thermal inputs and thermal losses. 
The following assumptions have been made for model construction [4]:

1. Only three layers of dermal parts epidermis, dermis and subcutaneous tissue have been considered, and their thicknesses are measured from skin surface towards body core.

2. Metabolic heat generation rate, thermal conductivity and blood perfusion rate in subcutaneous tissue are considered to be constant; corresponding parameters are considered to the dependent on thickness; thermal conductivity is considered to be constant in epidermis and metabolic heat generation and blood perfusion rate are considered to be zero in epidermis.

3. The field variable (temperature) at each layer is considered to be a quadratic polynomial.

4. Pennes bioheat equation has been used for the model simulation.

5. No air flow is considered.

The boundary conditions are:

1. Temperature at the interface of subcutaneous tissue and body core is $37^{\circ} \mathrm{C}$.

2. The heat transfer at the skin surface occurs due to convection, radiation and sweat evaporation, that is,

$$
-\left.k \frac{\partial T}{\partial \eta}\right|_{\text {at skin surface }}=h\left(T-T_{\infty}\right)+L E
$$

where $h\left(\mathrm{cal} / \mathrm{cm}^{2}-\min ^{\circ} \mathrm{C}\right)$ is the combined heat transfer coefficient due to convection and radiation, $T_{\infty}\left({ }^{\circ} \mathrm{C}\right)$ is the atmospheric temperature, $L(\mathrm{cal} / \mathrm{g})$ is the latent heat and $E\left(\mathrm{~g} / \mathrm{cm}^{2}-\min \right)$ is the sweat evaporation rate.

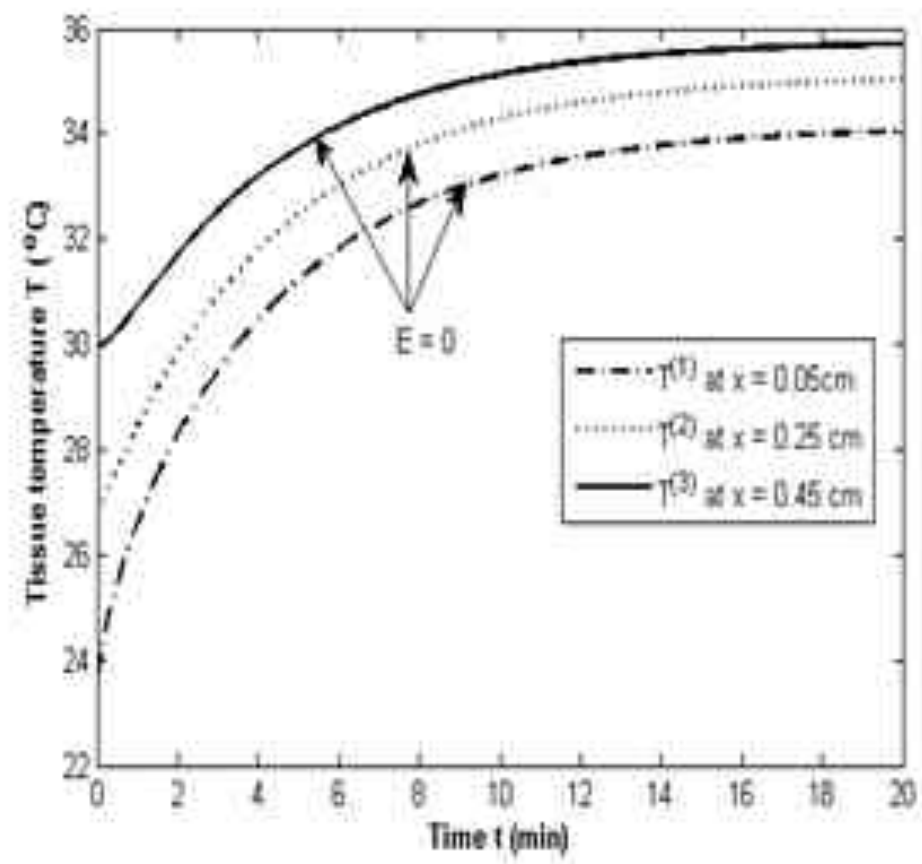

Figure 1. Transient temperature distribution at $T_{\infty}=15^{\circ} \mathrm{C}$ and $E=0$. 


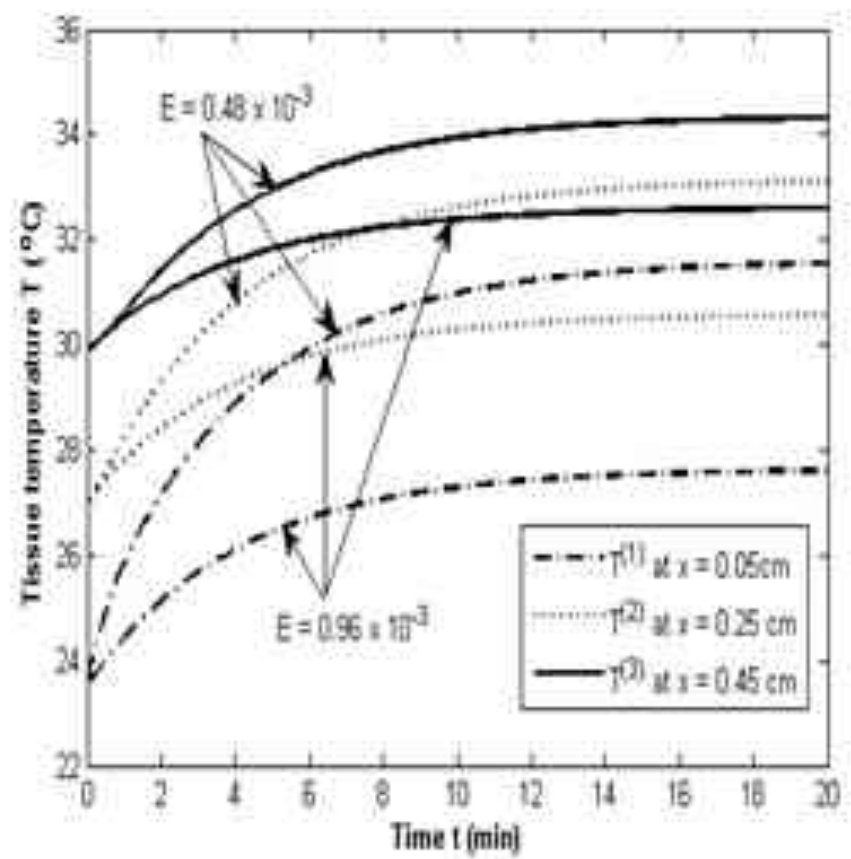

Figure 2. Transient temperature distribution at $T_{\infty}=33^{\circ} \mathrm{C}$ and $E=$ $0.48 \times 10^{-3}, 0.96 \times 10^{-3}$.

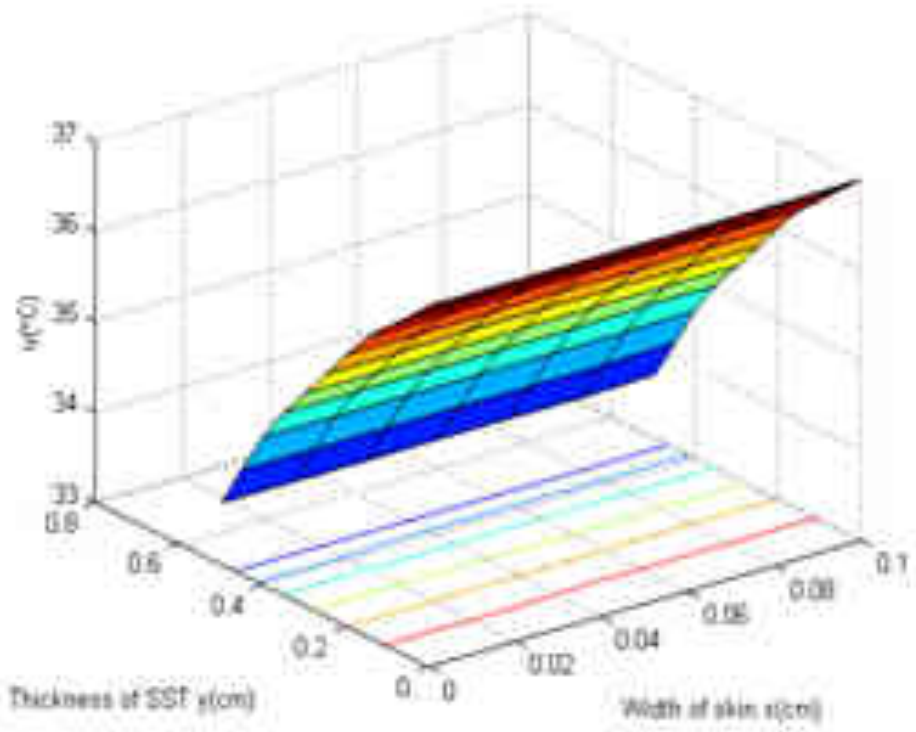

Figure 3. 2D temperature distribution at $T_{\infty}=33^{\circ} \mathrm{C}$ and $E=0.48 \times 10^{-3}$.

For numerical results, the following values of parameters are considered:

Thickness $(\mathrm{cm})$ :

Epidermis : 0.10; Dermis : 0.30; Subcutaneous tissue : 0.50

Thermal conductivity $\left(\mathrm{cal} / \mathrm{cm}-\min ^{\circ} \mathrm{C}\right)$ :

Epidermis : 0.030; 


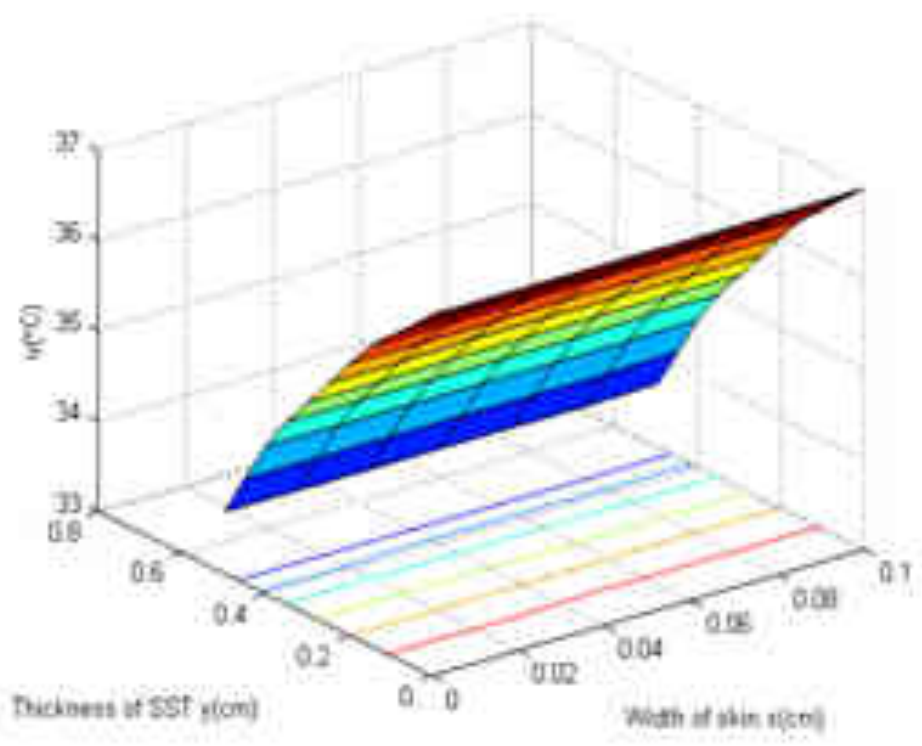

Figure 4. 2D temperature distribution at $T_{\infty}=33^{\circ} \mathrm{C}$ and $E=0.96 \times 10^{-3}$.

Dermis : as a linear function of thermal conductivities of epidermis and subcutaneous tissue;

Subcutaneous tissue : 0.0 .060

Blood perfusion: $M=\omega \rho_{b} c_{b}\left(\mathrm{~cm} / \mathrm{cm}^{3}-\min ^{\circ} \mathrm{C}\right)$

Epidermis : 0;

Dermis : as a linear function of $M$ of subcutaneous tissue;

Subcutaneous tissue : 0.0315

Metabolic heat generation rate $\left(\mathrm{cal} / \mathrm{cm}^{2}-\min ^{\circ} \mathrm{C}\right)$

Epidermis : 0;

Dermis : as a linear function of metabolic rate of subcutaneous tissue;

Subcutaneous tissue : 0.0 .060

Heat transfer coefficient $\left(\mathrm{cal} / \mathrm{cm}^{2}-\min \circ C\right)$

$h=0.009$

Latent heat $(\mathrm{cal} / \mathrm{g})$

$L=579$

The Rayleigh-Ritz finite element method together with Crank-Nicolson has been used to obtain the temperature distribution profiles in the layers of dermal parts. The temperature distribution profiles at a depth of $0.05,0.25,0.45 \mathrm{~cm}$ measured from outer skin surface in case of one dimension at $15^{\circ} \mathrm{C}$ and $33^{\circ} \mathrm{C}$ are shown respectively in Figure 1 and Figure 2. Figure 3 and Figure 4 present the steady state temperature distribution model for two dimensional discretized skin layers (Figure 5 ) at $33^{\circ} \mathrm{C}$ with evaporation rates $0.48 \times 10^{-3} \mathrm{gm} / \mathrm{cm}^{3}-\mathrm{min}$ and $0.96 \times 10^{-3} \mathrm{gm} / \mathrm{cm}^{3}-\min$. The graphs in Figures $1-4$ shows that there is significant effect of evaporation rate in temperature distribution in the layers of dermal part. 


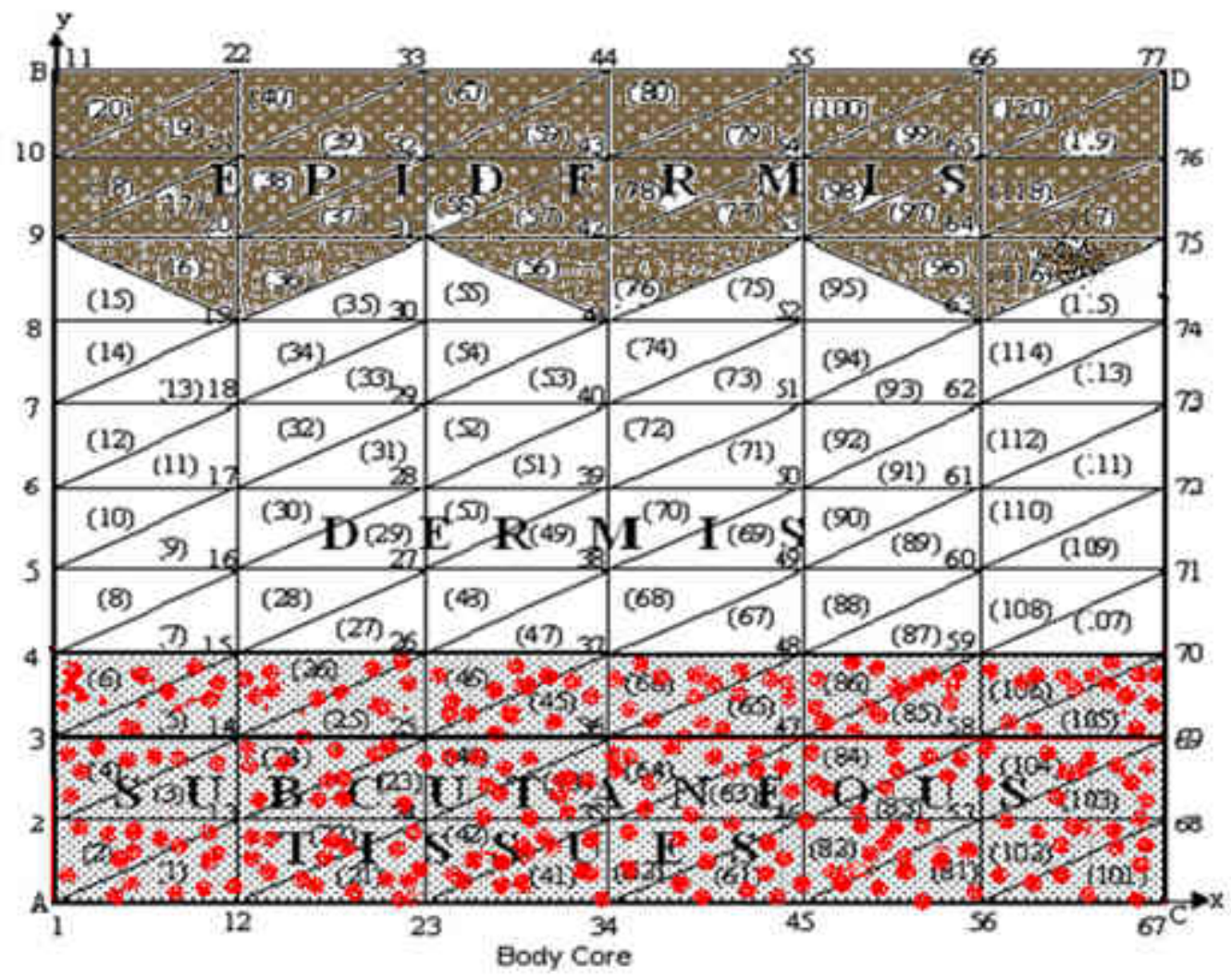

FiguRE 5. Discretization of skin layers.

4.2. Temperature Distribution Model in Human Eye. The following assumptions have been made by the authors [3] for model construction:

1. One dimensional temperature distribution model along papillary axis is considered.

2. The eye is modeled considering six major components cornea, aqueous humor, lens, vitreous humor, retina (with choroid) and sclera (Figure 6).

3. The effect of blood perfusion and metabolism is observed in retinal region only.

4. Pennes bioheat equation is used for model simulation.

5. No air flow.

The boundary conditions are

1. In the back of eye, heat is transferred from blood in the ophthalmic artery to the sclera:

$$
-k_{s} \frac{\partial T}{\partial \eta}=h_{b l}\left(T-T_{b l}\right)
$$

where $\eta$ the normal direction to the surface boundary, $k_{s}$ is the thermal conductivity of sclera, $h_{b l}$ is the heat transfer coefficient between blood and eye, and $T_{b l}$ is the blood temperature.

2. At the cornea, heat loss from the eye occurs through convection, radiation, and tear evaporation:

$$
-k_{s} \frac{\partial T}{\partial \eta}=h_{\infty}\left(T-T_{\infty}\right)+\sigma \epsilon\left(T^{4}-T_{\infty}^{4}\right)+E^{*}
$$


where $h_{\infty}$ represents the convection heat transfer coefficient between the cornea and ambient environment, $T_{\infty}$ is the ambient room temperature, $\sigma$ is the Stefan Boltzman constant $\left(5.67 \times 10^{-8} \mathrm{~W} / \mathrm{m}^{2}-K^{4}\right)$, is the emissivity of the cornea, and $E^{*}$ is the evaporative heat loss.

The presence of nonlinear radiation term in the boundary condition (4.3) makes the problem difficult to formulate. This difficulty can be resolved by introducing a suitable iterative procedure.

3. The inner body core temperature $T_{b}=37^{\circ} \mathrm{C}$.

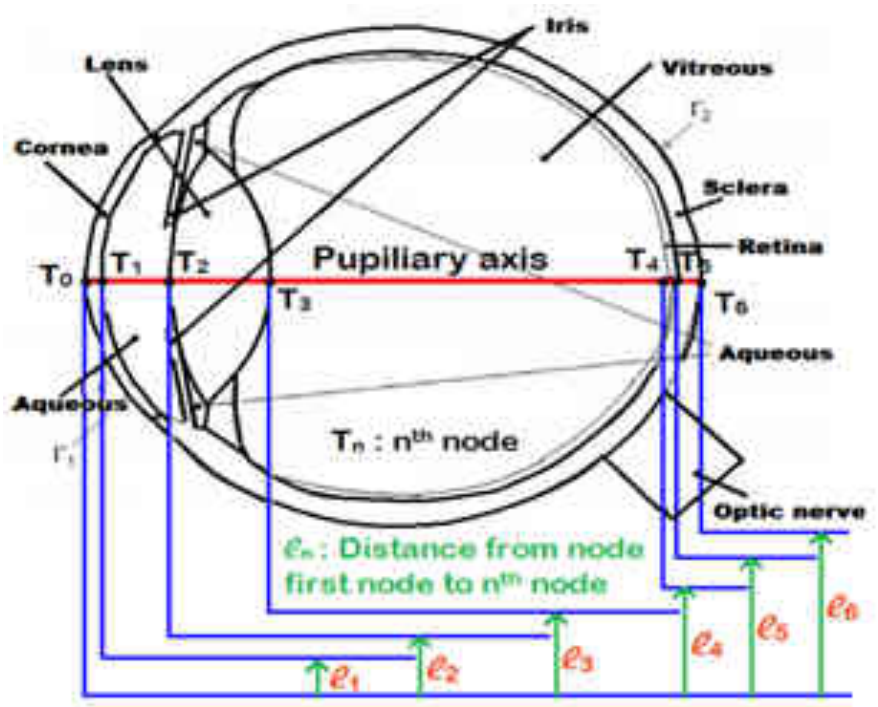

Figure 6. 1D discretization of human eye.

The variational finite element method with Crank Nicolson technique has been used to simulate the result. For the simulation of the results the parameter value considered are as follows: body core temperature $T_{b}=37^{\circ} \mathrm{C}$, evaporation rate $E^{*}=40 \mathrm{~W} / \mathrm{m}^{2}$, ambient convection coefficient $h_{a m b}=10 \mathrm{~W} / \mathrm{m}^{2}-^{\circ} \mathrm{C}$, blood convection coefficient $h_{b l}=65 \mathrm{~W} / \mathrm{m}^{2} \mathbf{-}^{\circ}$ $C$, blood density $\rho_{b}=1060 \mathrm{Kg} / \mathrm{m}^{3}$, blood specific heat $c_{b}=3594 \mathrm{~J} / \mathrm{Kg}-{ }^{\circ} \mathrm{C}$, initial guess $T_{1}^{0}=0$, and tolerance $\delta=0.0005$.

TABLE 1. Thermo physiological properties and thickness of different parts of human eye

\begin{tabular}{|c|c|c|c|c|}
\hline Tissue Type & $\begin{array}{c}\text { Thermal conductivity } \\
\left(W / m^{\circ} \mathrm{C}\right)\end{array}$ & $\begin{array}{c}\text { Blood perfusion } \\
\left(\mathrm{Kg} / \mathrm{m}^{3}\right)\end{array}$ & $\begin{array}{c}\text { Metabolic rate } \\
W / \mathrm{m}^{3}\end{array}$ & $\begin{array}{c}\text { Thickness } \\
\mathrm{mm}\end{array}$ \\
\hline Cornea & 0.580 & 0 & 0 & 0.50 \\
\hline Aqueous humor & 0.578 & 0 & 0 & 3.04 \\
\hline Lens & 0.400 & 0 & 0 & 4.00 \\
\hline Vitreous humor & 0.594 & 0 & 0 & 16.01 \\
\hline Retina & 0.565 & 35000 & 10000 & 0.50 \\
\hline Sclera & 0.580 & 0 & 0 & 1.05 \\
\hline
\end{tabular}


The transient temperature distribution of several parts of human eye for $t=5000$ seconds is presented in figure 7 and figure 8 below. The parameter values $E^{*}=40 \mathrm{~W} / \mathrm{m}^{2}$, and $T_{\infty}=10^{\circ} \mathrm{C}$ and $50^{\circ} \mathrm{C}$ are used for analysis. It can be seen from figure 7 and 8 that

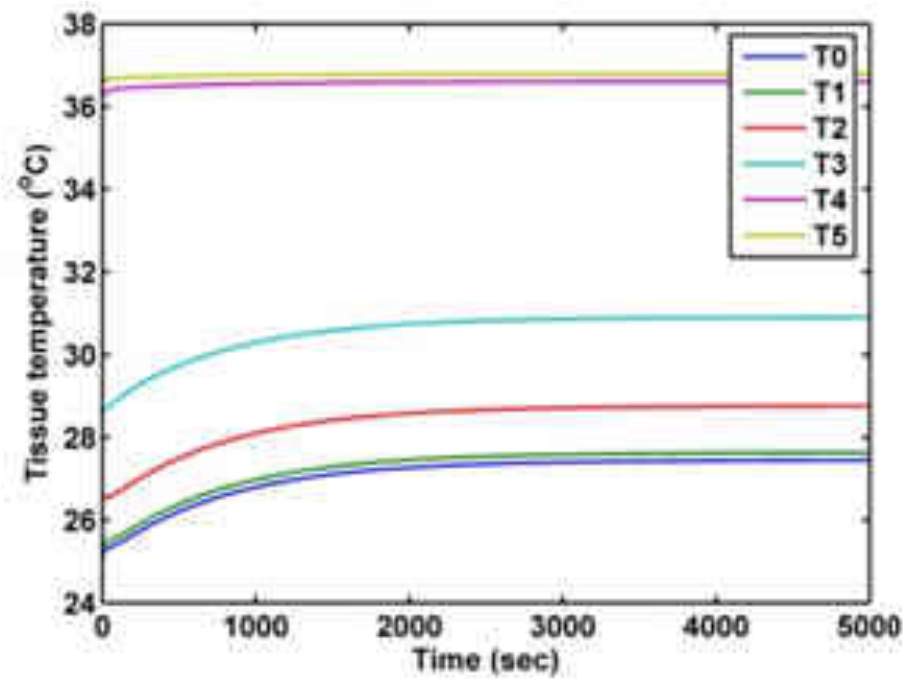

FiguRE 7. Temperature variation at $T_{\infty}=10^{\circ} \mathrm{C}$.

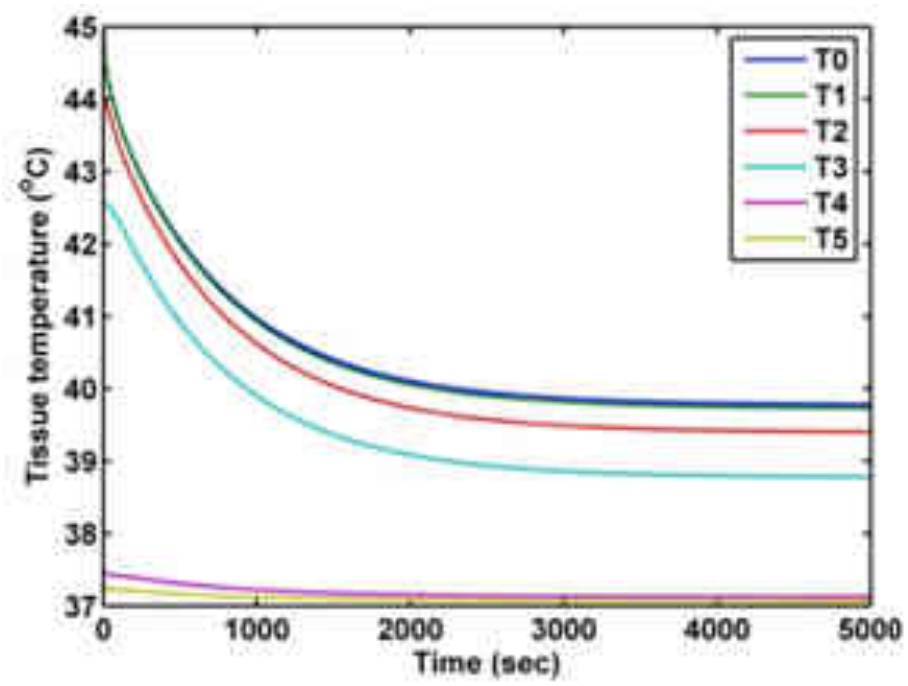

Figure 8. Temperature variation at $T_{\infty}=50^{\circ} \mathrm{C}$.

the anterior and posterior part of cornea, aqueous and lens temperatures begin to stabilize around 1870 seconds (approximately 31.17 minutes) and 2740 seconds (approximately 45.67 minutes) respectively. In human eye, heat gain occurs through conduction, perfusion, metabolism, blinking, tear flow, evaporation, and convection but heat loss occurs only through conduction, evaporation, convection and radiation. More factors are involved in heating eye components than cooling. Hence, eye is more vulnerable when it is exposed to high temperatures (high ambient temperatures, hyperthermia treatment, laser surgery etc) than low (low ambient temperatures, cryosurgery treatment etc). The temperature difference obtained between anterior and posterior parts of cornea are $0.2^{\circ} \mathrm{C}$ and $2.2^{\circ} \mathrm{C}$ respectively 
at $T_{\infty}=10^{\circ} \mathrm{C}$ and $T_{\infty}=50^{\circ} \mathrm{C}$. As well the temperature differences between anterior and posterior parts of lens are $0.05^{\circ} \mathrm{C}$ and $0.65^{\circ} \mathrm{C}$.

The corneal temperature distribution with and without blood perfusion and metabolism in retina at $T_{\infty}=10^{\circ} \mathrm{C}$ and $T_{\infty}=50^{\circ} \mathrm{C}$ are shown in figure 9 and figure 10 below.

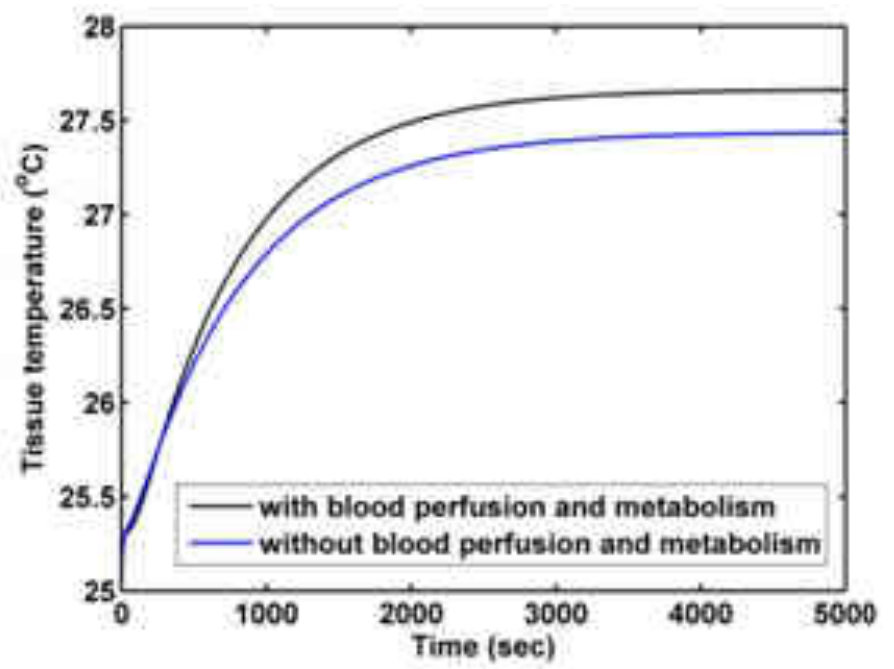

Figure 9. Temperature variation at $T_{\infty}=10^{\circ} \mathrm{C}$.

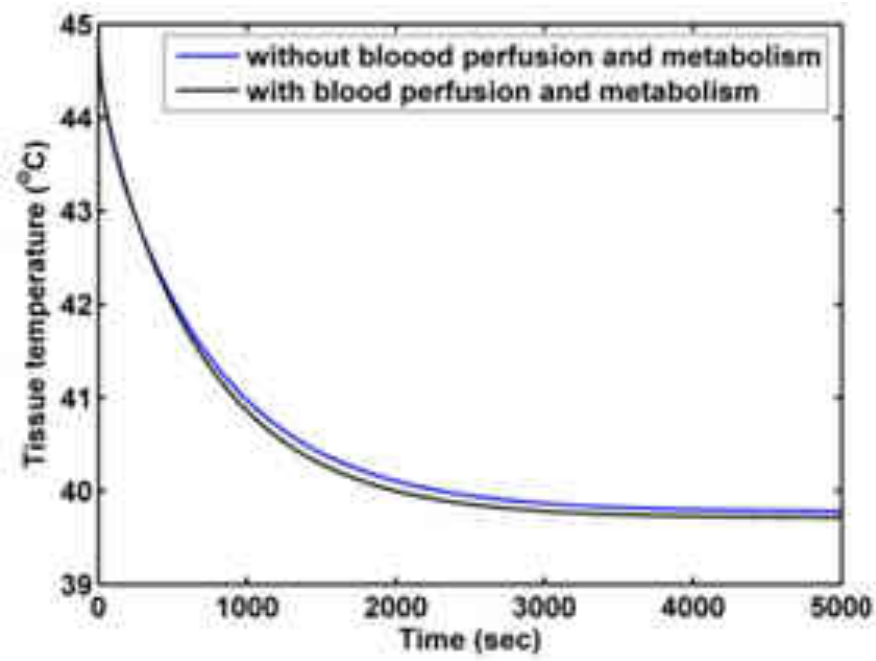

Figure 10. Temperature variation at $T_{\infty}=50^{\circ} \mathrm{C}$.

It can be observed from figures 9 and 10 that when corneal surface temperature is attained steady state in both cases, the temperature differences with and without blood perfusion and metabolism obtained are $0.23^{\circ} \mathrm{C}$ and $0.06 \circ C$ respectively. Steady state corneal surface temperature is reached earlier in case of having blood perfusion and metabolism in retina. Accordingly, steady state corneal surface temperature is reached earlier at $T_{\infty}=$ $10^{\circ} \mathrm{C}$ compared to that at $T_{\infty}=50^{\circ} \mathrm{C}$. This is due to better heating mechanism than cooling in eye. 
4.3. Burn Injury Model. Burn injury is a type of coagulative necrosis caused by heat transferred from source to the human body. This injury may not be only due to accidental burns but also due to prolonged exposure to hot industry or to sun and other situations. Thus the amount of tissue destruction is based on temperature and time of exposure. Guyton [6] mentioned that the average critical temperature for skin surface at which pain due to burn starts is $45^{\circ} \mathrm{C}$. At this temperature pain receptors in human body skin trigger. The human body feels uncomfortably hot if the skin surface temperature is $40^{\circ} \mathrm{C}$. On the basis of the damage suffered by the tissue due to any of the above causes the burns are classified as of first, second and third degree.

1. First degree burns: First degree burns involve minimal tissue damage and they effect only on the upper layer of skin, i.e, on epidermis layer only. This injury occurs if the steady temperature at skin surface rises about $45^{\circ} \mathrm{C}$ [6].

2. Second degree burns: Second degree burns affect both the epidermis and layers of dermis. The second degree burns occur if the steady temperature at skin surface rises about $72^{\circ} \mathrm{C}[17]$.

3. Third degree burns: Third degree burns damages all the layers of skin and subcutaneous tissue, i.e, this degree of burns damage epidermis, dermis and subcutaneous tissue layers.

The total injury in the layers of dermal part can also be classified depending on damage function, a non-dimensional number, based on Arrhenius integral

$$
\Omega(x, t)=A \int_{0}^{t} \exp \left[\frac{-\Delta E}{R T(x, t)}\right] d t
$$

where $A$ is frequency factor, $\Delta E$ is activation energy, $R$ is universal gas constant and $T$ is absolute skin surface temperature. The quantity $\Omega$ identifies various injury thresholds. The values of $\Omega$ equal to 0.53 and 1.0 represent respectively the injury threshold for first and second degree burns [11] and $10^{4}$ represents third degree burns [18]. The finite element method is used to simulate the temperature distribution model using the finite element discretization of two dimensional skin layers as shown in Figure 5 [5].

The figure 11 and figure 12 reveal that a temperature of $80^{\circ} \mathrm{C}$ and $120^{\circ} \mathrm{C}$ are respectively the threshold source temperature for first degree and second degree burns. From the figure 13, we observe that second degree burn occurs just before 12 minute if the applied source temperature is $90^{\circ} \mathrm{C}$. The figure 14 presents that there is a complete damage of dermal layer in few seconds (approximately 0.6 seconds) when applied source temperature is $120^{\circ} \mathrm{C}$.

The simulated results in figure 10-14 are obtained using the same parameter values as in temperature distribution model at stagnant air. Other parameter values are considered as:

$\Delta E=6.3 \times 10^{8} \mathrm{~J} / \mathrm{Kg}-\mathrm{mol}, \quad R=8.1336 \times 10^{3} \mathrm{~J} / \mathrm{kg}-\mathrm{mol}-\mathrm{K} \quad$ and $\quad A=18 \times 10^{99} / \mathrm{min}$ 


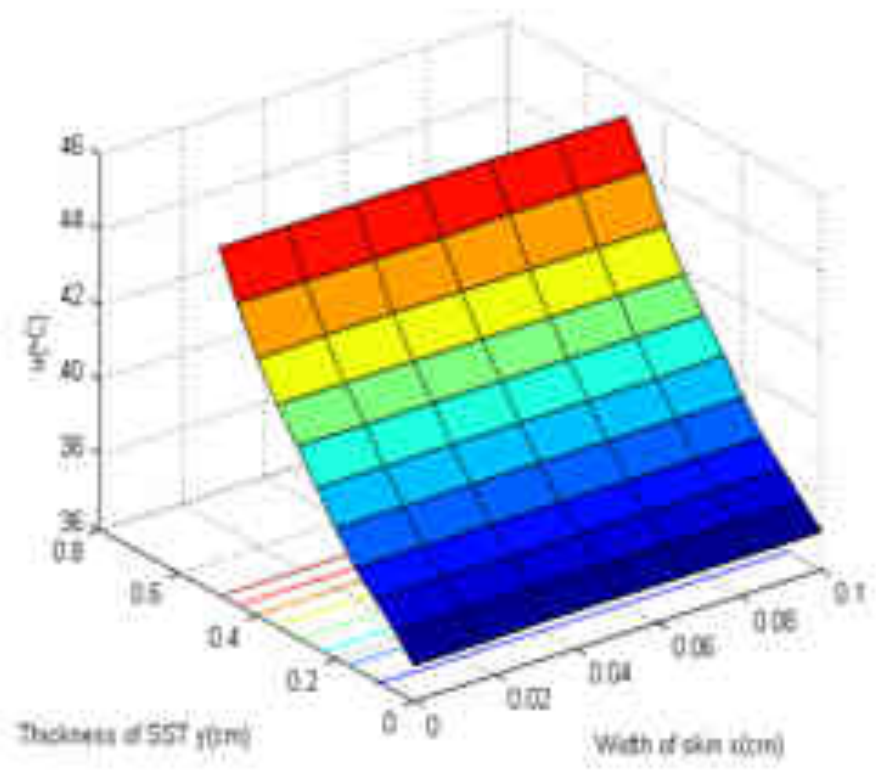

Figure 11. Dermal temperature rise at $T_{\infty}=80^{\circ} \mathrm{C}$.

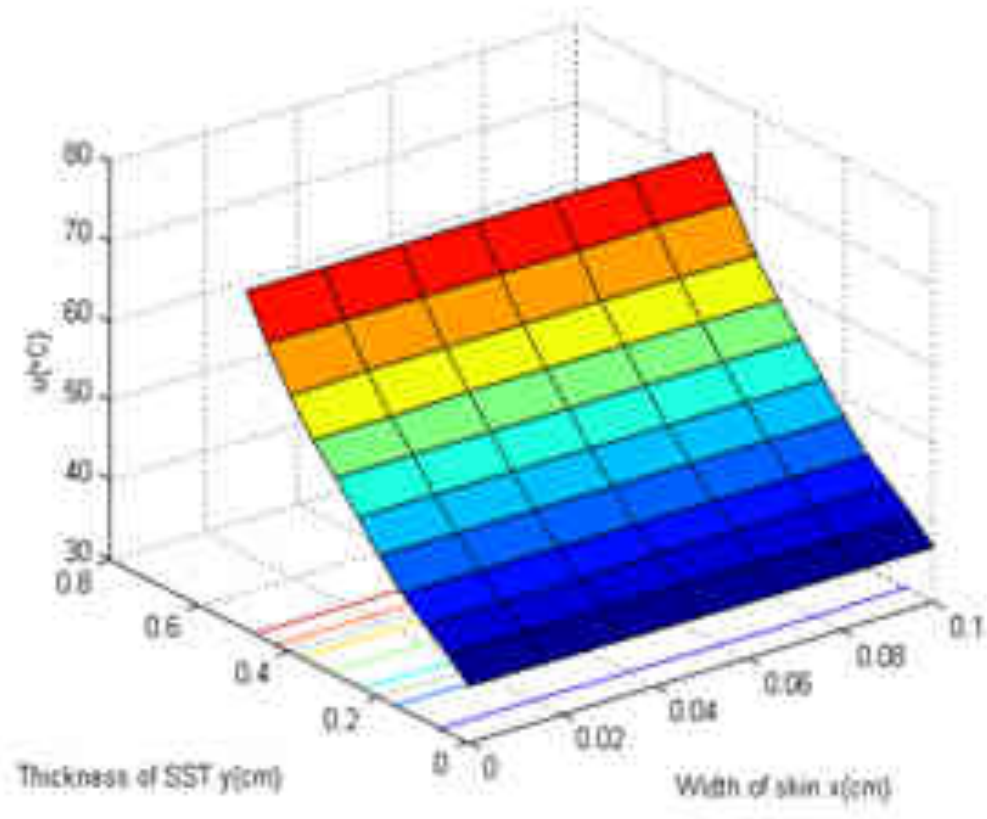

Figure 12. Dermal temperature rise at $T_{\infty}=120^{\circ} \mathrm{C}$.

4.4. Heat distribution in Tumor region. The temperature of the human body on the skin and subcutaneous layers depend on the metabolic activity, the blood flow and the temperature of the surroundings. Any abnormality in the tissue, such as the presence of a tumor, alters the normal temperature on the layers of dermal part due to increased metabolic activity of the tumor. Therefore, abnormal skin temperature profiles can be used as indicators of the status of malignancy due to uncontrolled metabolic activities. 


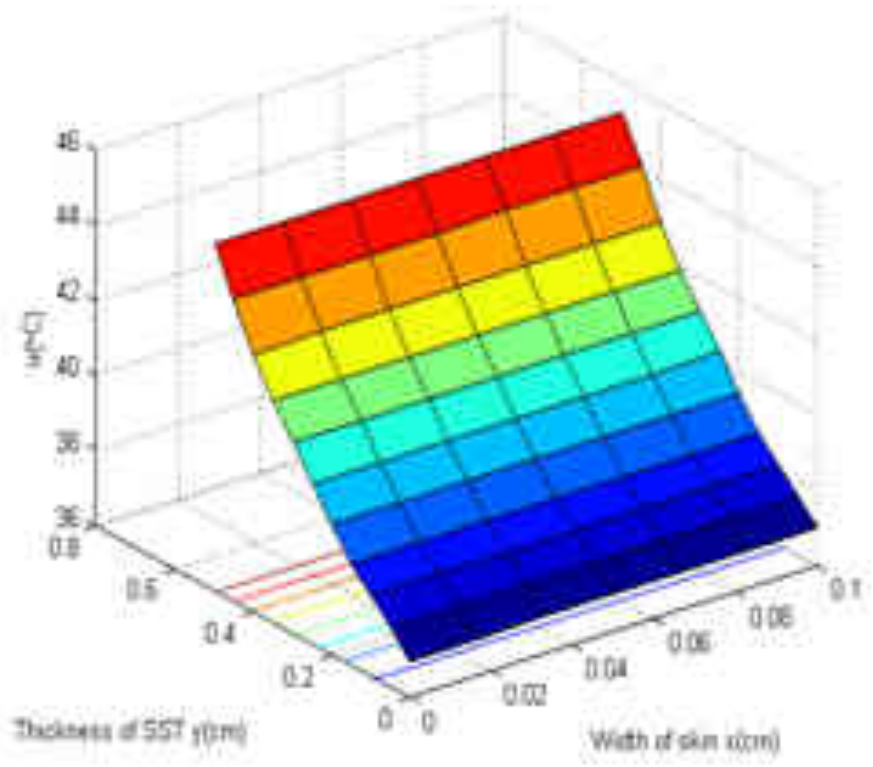

Figure 13. Burn damage for $T_{\infty}=90^{\circ} \mathrm{C}$.

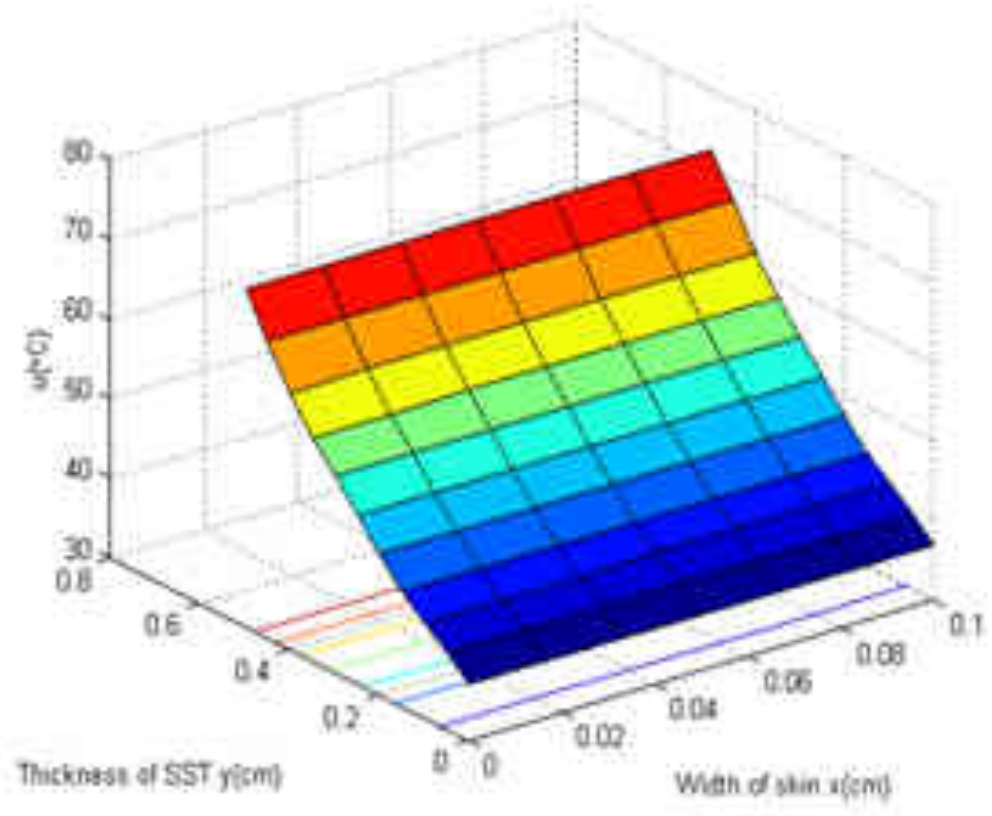

FiguRE 14. Burn damage for $T_{\infty}=120^{\circ} \mathrm{C}$.

The study explores the heat rise in the tumor region due to metabolic heat generation and sensible and insensible perspiration that help in maintaining uniform body core temperature. In the following model we have explored the temperature variation in the dermal layers due to tumor. Then the Pennes bioheat equation for heat distribution in the layers 


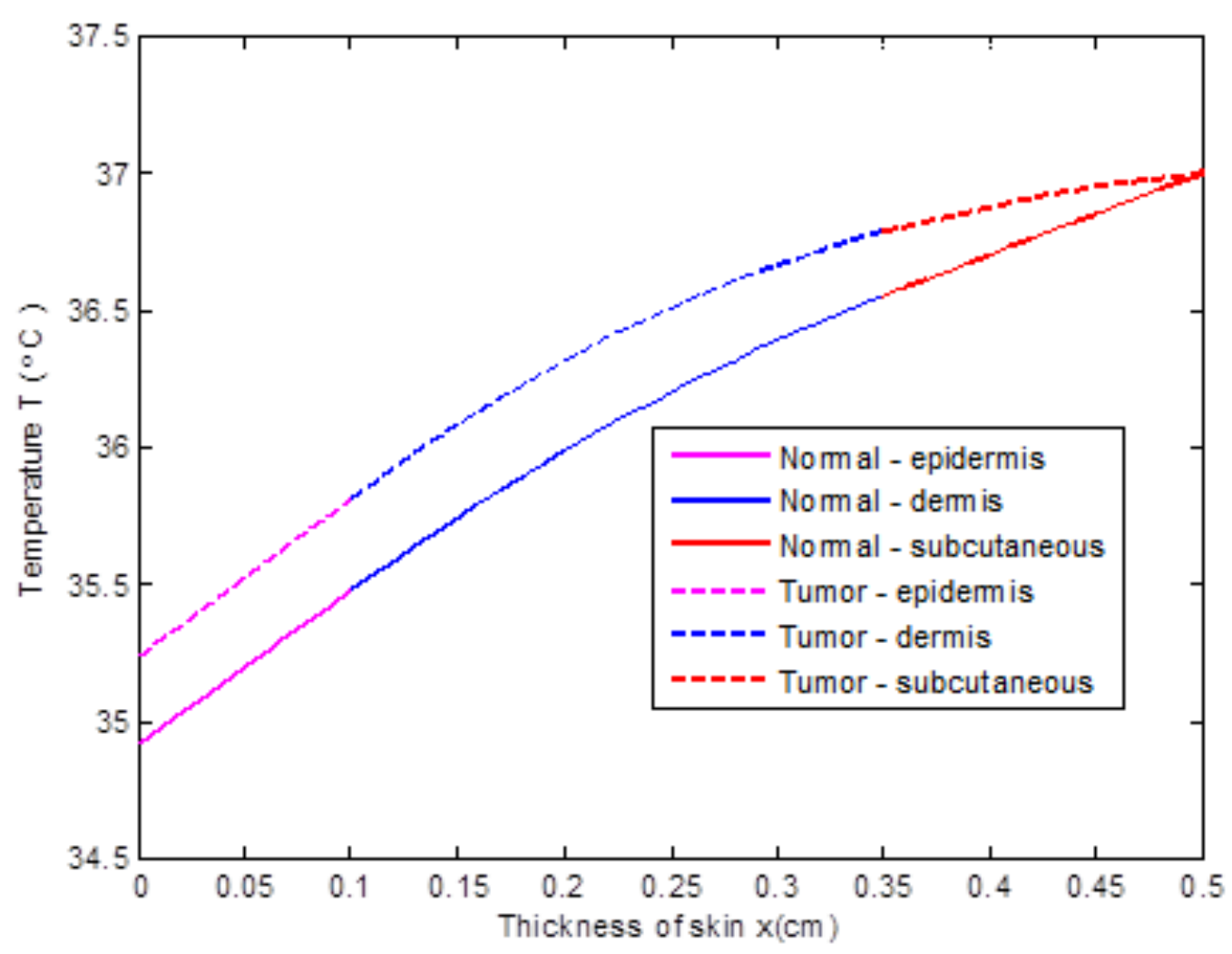

FiguRE 15. Temperature variation in normal and tumor cases.

of dermal region can be modified as

$$
\rho c \frac{\partial T}{\partial t}=\nabla \cdot(K \nabla T)+\rho_{b} c_{b} \omega\left(T_{a}-T\right)+q_{m}+q_{u}
$$

where $q_{u}$ is heat generated by uncontrolled process of malignant Tumor. We assume that tumor is situated in the layers of dermal region so it causes increase in metabolic activity, and in the model it is assumed to be constant in each layers. Figure 15 represents the variation of temperature profiles in skin layer with and without tumor. This variation is due to metabolic rise in tumor cell.

4.5. Conclusion. Most of the investigators concerns are the application sides of bioheat transfer in living tissue, and others are to develop bioheat equation only to overcome the shortcomings in Pennes model arises due to blood perfusion. Due to the complexity of vascular geometry, there are two theoretical approaches describing the effect of blood flow in a biological system. (i) Continuum Model - In this approach the effect of blood flow in the region of interest is averaged over a control volume, (ii) Vascular Model - In this approach blood vessels are represented as tubes buried in tissue. Few investigators concerns are for non-Fourier bioheat transfer model, and this kind of model is a new approach of research for bioheat transfer. 
Volume averaging theory is also a field to study for formulation and application of bioheat equation. But still it is hard to use. Only few researchers have attempted its Pennes version for temperature distribution in human body.

ACKNOWLEDGEMENT I acknowledge the anonymous reviewer for the suggestions and queries to improve this paper.

\section{REFERENCES}

[1] C.K.Charny Mathematical models of Bioheat transfer, Advances in heat transfer, Vol. 22, pp 19-155, 1992.

[2] M.M.Chen, K.R.Holmes, Microvascular contribution in tissue heat transfer, Annals New York Academy of Sciences, Vol. 335,pp 137-150, 1980.

[3] K.C.Gokul, D.B.Gurung, P.R.Adhikary, FEM approach for transient heat transfer in human eye, Applied Mathematics, Vol. 4, pp 30-36, 2013.

[4] D.B.Gurung, V.P.Saxena, P.R.Adhikary, FEM approach to one dimensional unsteady state temperature distribution in human dermal parts with quadratic shape functions, J. Appl. Math. \& Informatics, Vol. 27 (1 \& 2), pp 301-313, 2009.

[5] D.B.Gurung, V.P.Saxena, P.R.Adhikary, Mathematical estimation of unsteady state burn damage due to hot temperature, The Nepali Math. Sc. Report, Vol. 27 (1 \& 2),pp 75-84, 2007.

[6] A.C.Guyton, J.E.Hall, Textbook of medical physiology, tenth edition, Indian reprint, W.B.Saunders, 2004.

[7] L.M.Jiji, Heat transfer in living tissue, Heat conduction, 3rd edition, Springer, pp 302-346, 2009.

[8] K.Khanafer, K.Vafai, Synthesis of mathematical models representing bioheat transport, Advances in Numerical heat transfer, CRC Press, Vol. 3(2009), pp 1-28, 2009.

[9] J.J.Lagendijk, A mathematical model to calculate temperature distributions in human and rabbit eyes during hyperthermia treatment, Phys Med Bio., Vol. 27, pp 1301-1311, 1982.

[10] T.W.McGrail, R.C.Seagrave, Application of the Bioheat Transfer Equation in Fetal-Placental Studies, Annals N.Y.Acad.Sci., Vol. 335, pp 161-172, 1980.

[11] A.R.Moritz, F.C.Henrique, Studies of thermal injury I: The conduction of heat to and through skin and the temperature attained therein. A theoretical and an experimental investigation, Amer. J. Path., Vol. 23, pp 531-549, 1947.

[12] A.Nakayama, Y.Sano, K.Yoshikawa, A rigorous derivation of the bioheat for local tissue heat transfer based on a volume averaging theory, Heat and Mass transfer, Vol. 46, pp 739-746, 2010.

[13] H.H.Pennes, Analysis of tissue and arterial blood temperature in resting forearm, Journal of applied physiology, Vol. 1, pp 93-122, 1948.

[14] W.Perl, Heat and matter distribution in body tissues and the determination of tissue blood flow by local clearance methods, J.Theoret. Biol. Vol. 2, pp 201-235, 1962.

[15] D.Poljak, A.Peratta, C.Brebbia, The boundary element electromagnetic Thermal Analysis of Human Exposure to Base Station Antennas Radiation, Engin. Anal. Bound. Elem., Vol. 28,pp 763-770, 2004.

[16] M.Quintard, S.Whitaker, One and two equation models for transient diffusion processes in two phase system, Advances in Heat transfer, Vol. 23, pp 369-464, 1993.

[17] V.P.Saxena, Mathematics of thermal abnormalities in outer human body, Mathematical modeling: Real life problems and computer applications, Anamaya Publisher, New Delhi, pp 1-26, 2006.

[18] A.N.Takata, Zaneveld L, Ritcher W, Laser-induced thermal damage of skin, SAM-TR-38, USAF School of Aerospace Medicine, 1977.

[19] S.Weinbaum, L.M.Jiji, A new simplified bioheat equation for the effect of blood flow on local average tissue temperature, Journal of Biomechanical Engineering, Vol. 107, pp 131-139, 1985. 
[20] S.Weinbaum, L.M.Jiji, D.E.Lemons, Theory and experiment for the effect of vascular microstructure on surface tissue heat transfer Part II: Model formulation and solution, ASME J of Biomechanical Engineering, Vol. 106, pp 331-341, 1984.

[21] W.Wulff, The energy conservation equation for living tissue, IEEE Transactions on Biomedical Engineering, Vol. 21 (6), pp 494-495, 1974.

[22] L.Zhu, Heat transfer applications in biological systems, Bimedical Engineering and design, Vol. 1, pp 33-67, 2003.

1 School of Science, Kathmandu University 


\section{THE NEPALI \\ MATHEMATICAL SCIENCES \\ REPORT}

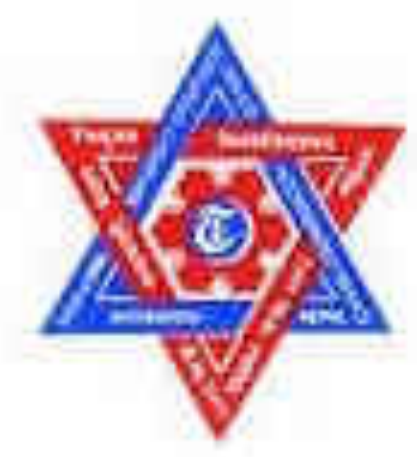

Published by

CENTRAL

DEPARTMENT OF MATHEMATICS

TRIBHUVAN UNIVERSITY

KATHMANDU, NEPAL 


\title{
THE NEPALI \\ MATHEMATICAL SCIENCES \\ REPORT
}

\author{
Chief Editor \\ Kedar Nath Uprety \\ Central Department of Mathematics \\ Tribhuvan University, Nepal
}

\section{Editorial Board}

Dhruba R. Adhikari (Kennesaw State University, USA)

Prakash Muni Bajracharya (Tribhuvan University, Nepal)

Chet Raj Bhatta (Tribhuvan University, Nepal)

Maya Chhetri (The University of North Carolina, USA)

Tanka Nath Dhamala (Tribhuvan University, Nepal)

Maciej Dunajski (Clare College, University of Cambridge, UK)

Santosh Ghimire (Tribhuvan University, Nepal)

Dil Bahadur Gurung (Kathmandu University, Nepal)

Jivandhar Jnawali (Tribhuvan University, Nepal)

Durga Jang K.C. (Tribhuvan University, Nepal)

Shree Ram Khadka (Tribhuvan University, Nepal)

Bishnu Prasad Lamichhane University of Newcastle, Australia

Narayan Prasad Pahari (Tribhuvan University, Nepal)

Mahendra Panthee (State University of Campinas Campinas, São Paulo, Brazil)

Francesco Pappalardi (Roma Tre University, Italy)

Gerhard Pfister (TU Kaiserslautern, Germany)

Stephan, Ruscheweyh (University of Wurzburg, Germany)

Hinonori Shiga (Chiba Univeristy, Japan)

Christian James Schmeiser (University of Vienna, Austria)

Ajaya Singh (Tribhuvan University, Nepal)

Naveen Vaidya (San Diego State University,USA)

Michel Waldschmidt (Université Pierre et Marie Curie, France)

Roger Wiegand University of Nebraska, USA

Sylvia Wiegand University of Nebraska, USA 


\section{Advisory Board}

Hom Nath Bhattarai (Tribhuvan University, Nepal)

Santosh Man Maskey (Tribhuvan University, Nepal)

Shankar Raj Pant (Tribhuvan University, Nepal)

Ram Man Shrestha (Tribhuvan University, Nepal)

Bhadra Man Tuladhar (Kathmandu University)

Gajendra Bahadur Thapa (Tribhuvan University, Nepal) 